\title{
ОЦЕНКА ИНТЕЛЛЕКТУАЛЬНОГО КАПИТАЛА ОРГАНИЗАЦИИ
}

\author{
(c) 2020 Александров Игорь Николаевич \\ кандидат экономических наук, доцент \\ Санкт-Петербургский политехнический университет Петра Великого, Россия, Санкт-Петербург \\ E-mail: a7830298@gmail.com \\ (c) 2020 Рассказова Ольга Анатольевна \\ кандидат экономических наук, доцент \\ Санкт-Петербургский политехнический университет Петра Великого, Россия, Санкт-Петербург \\ E-mail: olanka777@yandex.ru

\section{(c) 2020 Бурмистров Андрей Николаевич} \\ кандидат экономических наук, доцент \\ Санкт-Петербургский политехнический университет Петра Великого, Россия, Санкт-Петербург \\ E-mail: isar@mail.ru

\section{(c) 2020 Синявина Мария Павловна \\ старший преподаватель} \\ Санкт-Петербургский политехнический университет Петра Великого, Россия, Санкт-Петербург \\ E-mail:sinmp@inbox.ru
}

Данная статья направлена на исследование и совершенствование методов оценки нематериальных активов коммерческих организаций. Именно нематериальные активы являются основным фактором определяющим конкурентоспособность компании в настоящее время. Адекватная оценка нематериальных активов и поиск направлений повышения их стоимости становится важной задачей оперативного и стратегического управления. В работе выявляются проблемы оценки нематериальных активов компании. Авторами предложена методика оценки экономического потенциала компании. Данная методика основана на модификации доходного подхода к оценке бизнеса и позволяет оценивать нематериальную составляющую стоимости организации (интеллектуальный капитал). Использование предложенной методики позволяет оценивать, как интеллектуальный капитал (и его составляющие), так и изменение интеллектуального капитала в результате реализации перспективных инвестиционных проектов.

Ключевые слова: нематериальные активы, потенциал, интеллектуальный капитал, материальные активы, структурный капитал, стратегическое управление.

Актуальность данного исследования обусловлена тем, что в настоящее время в большинстве отраслей мировой экономики именно нематериальные активы определяют уровень ресурсного потенциала компании и, соответственно, ее долгосрочные конкурентные преимущества.

Капитализация современной организации может в десятки раз превосходить стоимость активов учтенных на ее балансе.

Данная разница является оценкой рынком реальной стоимости неосязаемых интеллектуальных активов фирмы.

Наличие у организации технологий, систем управления, репутации, а также персонала с высоким уровнем компетенции, который соответствует решаемым задачам, определяют ее долгосрочную конкурентоспособность. И все это включая человеческий капитал компании, формирует ее потенциальную стоимость.

Рыночная экономика дает принципиальную возможность России эффективно повышать национальный потенциал благодаря широкому использованию разнообразных рыночных механизмов.

С другой стороны недостаточный уровень располагаемых человеческих ресурсов, недостаточная производительность труда и является одной системных проблем современных российских компаний, мешающих эффективно 
использовать иные материальные и нематериальные ресурсы.

В начале данной работы видится необходимым устранить некоторые терминологические несоответствия, которые встречаются в литературе относительно такого явления как нематериальные активы. В бухгалтерском учете под нематериальными активами подразумевают только те активы, которые по своим характеристикам могут быть учтены на балансе (например, права интеллектуальной собственности, лицензии и т.п.). Причем часто стоимость учета в бухгалтерской отчетности данных активов не соответствует их реальной рыночной стоимости.

Данное расхождение может приводить, как к ситуации, когда нематериальный актив учитывается по заниженной стоимости, так и наоборот (когда на балансе фигурируют нематериальные активы, имеющие реально более низкую стоимость, чем это отражено в документах).

Так же важно понимать, что нематериальные активы могут очень быстро менять свою рыночную стоимость в результате изменения факторов внутренней и внешней среды. Внешняя среда чаще является причиной данных изменений (например, стоимость уникальной технологии может обесцениться в результате появления данной или похожей технологии у конкурентов или изменения законодательства).

Термин нематериальные активы также используют менеджеры, но они вкладывают в него более широкое понимание активов, чем это принято в бухгалтерском учете.

Расхождение обусловлено несколькими факторами. Главным из них является сложность или даже невозможность адекватно учесть на балансе целый ряд интеллектуальных активов (компетентный персонал, репутацию, внешние ресурсы). Крайне сложно отразить в бухгалтерском учете различные информационные ресурсы, которыми располагает компания.

Поэтому для адекватного восприятия понятия нематериальных ресурсов в данной работе в основном будет использоваться термин «интеллектуальный капитал».

Под интеллектуальным капиталом (ИК) компании принято понимать [3] «активы, представляющие собой мысленные знания, то есть не отделимые от сотрудников, и знания, воплощенные в результатах мыслительной деятельности (структурах, интеллектуальной собственности, клиентах и др.)».
Как уже отмечалось, необходимость введения термина интеллектуальный капитал обусловлено путаницей в терминах используемых в настоящее время экономистами, управленцами, оценщиками и бухгалтерами.

Стоимость данного капитала, в современных коммерческих организациях, может многократно превышать стоимость ее иных активов, что делает качественное управление данным ресурсом важнейшей задачей.

Интеллектуальный капитал организации это знания воплощенные в результатах интеллектуальной деятельности компании и знания ее сотрудников.

Достаточно часто, ключевой составляющей общего Интеллектуального капитала (ИК) небольших организации является именно Человеческий капитал (ЧК), так как именно люди являются носителями необходимых компании знаний и умений. Наряду с Человеческим капиталом в Интеллектуальный капитал входят Рыночный капитал (РК) и Структурный капитал (CK).

CK- это первую очередь инфраструктура компании (системы позволяющие ей эффективно работать, например информационные системы, системы управления закупками, запасами, производством и т.п.), а также права интеллектуальной собственности (патенты, лицензии).

В рыночном капитале формируется репутацией компании и тем, что вытекает из репутации. Под РК понимаются также лояльность и удовлетворенность потребителей.

Иногда сложно или даже невозможно отнести некоторые активы только к одной составляющей интеллектуального капитала. Важно понимать, что конкурентные преимущества создаются в основном уникальным сочетанием составляющих интеллектуального капитала и материальных активов.

Стратегическое управление направленно на достижение соответствия уровня ресурсов компании и в первую очередь интеллектуального капитала, задачам организации и призвано повысить конкурентоспособность компании и способствовать выполнению ее миссии.

Для объективной оценки усилий менеджмента по развитию и сбережению интеллектуального капитала требуются соответствующие методики, которые не всегда совершенны $[2,4]$.

В настоящее время нет единой общепризнанной экспертным сообществом методики 
измерения Интеллектуального капитал организации.

В настоящее время, с помощью общеизвестных методов оценки бизнеса, управляющие и собственники могут достаточно объективно оценить эффективность вложения капитала в формирование материных активов. Сопоставляя доходы и затраты на мероприятия можно, с высокой долей вероятности, сделать вывод о целесообразности тех или иных инвестиционных вложении. Инвестиции в интеллектуальный капитал не поддаются классической оценке.

Мероприятия, направленные на развития интеллектуального капитала компании должны соответствовать общей стратегии организации.

Ниже приведен предлагаемый авторами подход к оценке интеллектуального капитала построенный на основе подхода к оценке общего потенциала [1].

Задачей является определение интеллектуального капитала и определение приращения интеллектуального капитала организации в результате запланированных мероприятий. Если приращение положительным, то мероприятия будут признаны целесообразными.

Под потенциалом мы будем понимать меру возможностей компании, выраженную в деньгах. Ближе всего данная мера соотносится со стоимостью компании.

Оценка потенциала, как и оценка цены компании, строится на стоимости материальных активов, так и интеллектуального капитала.

Обычно Интеллектуальный капитал приблизительно оценивают путем вычитания стоимости чистых материальных активов организации из общей рыночной стоимости компании.

Для определения рыночной стоимости компании, чаще всего, нужна рыночная оценочная экспертиза, так как далеко не все организации свободно торгуются на бирже. Видится возможным предложить оценивать стоимость интеллектуального капитала как разницу между стоимостной оценкой потенциала организации и стоимостью ее чистых материальных активов. Так как потенциал является совокупным показателем всех ресурсов и возможностей организации, интеллектуальны капитал целиком может быть оценен по формуле:

$$
U^{k}=P^{k}-A_{m}{ }^{k}
$$

Оценив потенциал, мы может определить значение интеллектуального капитала.

Для этого предлагается использовать один из подходов к оценке бизнеса (доходный).

Данных подход к оценке стоимости бизнеса предполагает учет возможных денежных потоков от его деятельности. Предлагается развитие данного подхода к оценке для определения потенциала [1]. Необходимо выделить некоторое количество самых перспективных инвестиционных проектов (ПИП) и рассчитать сумму чистых приведенных стоимостей (NPV) от них при анализе потенциала компании. Kроме NPV перспективных инвестиционных проектов (ПИП) предлагается при оценке потенциала предприятия рассчитать постпрогнозную стоимость активов (ПСА) после окончания проектов:

$$
P^{k}=F^{k}+C^{k}
$$

где $P k$ - потенциал $\mathrm{k} ; F k$ - сумма чистых приведенных стоимостей перспективных инвестиционных проектов для компании $\mathrm{k} ; C^{k}-n o-$ стпрогнозная стоимость активов компании $\mathrm{k}$ на конец периода планирования.

Перспективные инвестиционные проекты это те проекты которые предположительно будут иметь максимальный суммарный NPV. Bыбор и прогнозирование данных проектов может осуществляться как силами менеджеров компании, так и внешними экспертами.

Перспективные инвестиционные проекты состоят из трех групп и включают: Реализуемые проекты $(\mathrm{p} 11, \ldots, \mathrm{p} 1 \mathrm{w})$, Запланированы к реализации проекты (p21,..., p1q) и Потенциально возможные к реализации проекты (p31,.., p3g).

Таким образом, $F k$ сумма чистых приведенных стоимостей предпочтительных инвестиционных проектов будет рассчитываться как:

$$
F^{k}=\sum_{i=1}^{w} N P V\left(p_{1 i}\right)+\sum_{j=1}^{q} N P V\left(p_{2 j}\right)+\sum_{t=1}^{g} N P V\left(p_{3 t}\right)(3)
$$

Авторы предполагают, что разделение общего денежного потока на отдельные потоки от реализуемых, запланированных к реализации и потенциально возможных проектов позволит индивидуально оценить риски каждого. Постпрогнозная стоимость активов $\left(C^{k}\right)$ рассчитывается на конец периода планирования.

Вышеперечисленные формулы могут позволить получить значение потенциала и интеллектуального капитала (как разницы между оценкой потенциала и чистыми материальными 
активами). Предложенный подход к оценке потенциала достаточно универсален.

Если рассчитать значения потенциала и интеллектуального капитала компании на момент оценки и вероятное значение данных показателей в случае реализации мероприятий, то в случае их положительного изменения, мероприятия могут считаться целесообразными.

Предложенные подход может так же использоваться при оценке эффективности сделок слияний (формула 4) поглощений (формула 5). В формуле $5 \mathrm{~d}$ - это доля в общей компании, которую получали аукционеры анализируемой компании. Здесь также получив значения приращения потенциала и интеллектуального капитала можно оценить целесообразность потенциальной сделки.

$$
\Delta P_{n}^{k}=F^{k+l}+C^{k+l}-F^{k}-C^{k}
$$

$$
\Delta P_{c}^{k}=\left(F^{k+l}+C^{k+l}\right) * d-F^{k}-C^{k}
$$

В качестве основных выводов необходимо отметить следующее:

Применение предложенного подхода не ограничивается только оценкой потенциала. C помощью анализа приращения потенциала, подход дает возможность проводить оценку решений по предполагаемым слияниям, поглощениям или крупным инвестиционным проектам. Так же продолженный метод может использоваться при оценке эффективности возможных сделок, связанных с дезинтеграцией.

Применение данного подхода для оценки потенциала и интеллектуального капитала может быть полезным дополнительным инструментом для оценки эффективности многих мероприятий направленных на организационные изменения.

\section{Библиографический список}

1. Александров И.Н. Оценка интеллектуального капитала через призму экономического потенциала организации // Проблемы современной экономики, - № 3-2016.

2. Ильин И.В., Ростова О.В. Управление инвестициями. - СПБ.: Изд-во Политехн. Ун-та, 2017. - 244 с.

3. Козырев А.Н. Экономика интеллектуального капитала. Научные доклады -№ 7-2006. СПб.: НИИ менеджмента СПбГУ, 2006. С .30

4. Ростова О.В. Бюджетирование как инструмент контроллинга. В сборнике: Стратегическое управление организациями: современные технологии 2017. С. 364-371. 